\title{
ENHANCEMENT IN STEADY STATE AND DYNAMIC PERFORMANCE OF DIRECT TORQUE CONTROL INDUCTION MOTOR DRIVE
}

\author{
Bhoopendra Singh ${ }^{*}$ — Shailendra Jain ${ }^{* *}$ — Sanjeet Dwivedi ${ }^{* * *}$
}

\begin{abstract}
An enhancement in dynamic performance of a traditional DTC drive can be achieved by a robust speed control algorithm while the steady state performance depends upon the switching strategy selected for minimization of torque ripples and an efficient flux control loop. In this paper a new torque ripple reduction technique with a modified look up table incorporating a larger number of synthesized non zero active voltage vectors is utilized to overcome the limitations of the conventionally controlled DTC drive. A fuzzy logic based speed controller and a low pass filter with tunable cutoff frequency for flux estimation is proposed in this paper. The proposed study is investigated through simulation and experimentally validated on a test drive. logic

K e y w or d s: direct torque control (DTC), induction motor, torque ripple minimisation, modified low pass filter, fuzzy
\end{abstract}

\section{INTRODUCTION}

In a direct torque control induction motor drive, the basic concept is to control both stator flux and electromagnetic torque of the machine simultaneously by the application of one of the six active full voltage vectors and two zero voltage vectors generated by an inverter. The stator flux and torque track their reference values within the limits of two hysteresis bands with two hysteresis comparators and a heuristic switching table to obtain quick dynamic response [1-4]. Torque and current ripples with variable switching operation are the major concerns with a basic DTC drive.

In the past decades as reported in literature, DTC based on Space Vector Modulation (DTC-SVM) is one of the most popular solution for the mitigation of above mentioned short comings of conventional DTC drive [57]. A constant frequency operation with reduced torque and current ripples, but at the expense of increased complexity are the highlights of implementing a DTC drive with Space Vector Modulation.

Another approach for torque ripple minimization is to replace a two level inverter with a multilevel inverter [8-11]. Availability of more voltage vectors for a given requirement of torque and flux resulted into an improved response of the drive in terms of torque ripples, but at the cost of enhancement in control complexity and a higher device count. Thus affecting the robustness, simplicity in control and reliability of the drive which are the key features of a DTC drive.

In a conventional DTC drive, increased torque and current ripples are also attributed to the application of a single voltage vector for the entire sampling period. These ripples can be easily reduced by applying the selected voltage vector only for a part of the sampling period.
This technique, also known as duty ratio control [1215], results in an increased number of voltage vectors beyond the available ones, without any increase in the number of semiconductor switches in the inverter. The duty ratio control technique requires frequent application of zero voltage vectors, which provokes some problems such as the demagnetization phenomenon of the stator flux, especially in the low speed region.

In this paper an improvement in the steady state as well as dynamic performance of a DTC drive is proposed by implementing the DTC algorithm with the following modifications.

1. An efficient switching scheme for torque ripple reduction.

2. A robust speed control algorithm for a fast dynamic response.

3. A modified flux estimation algorithm for the flux control loop.

A new simple torque ripple reduction technique with help of a modified look up table incorporating a larger number of synthesized non zero active voltage vectors generated by a two level voltage source inverter is proposed for minimizing the torque ripples.

A low pass filter based digital integration algorithm with tunable cutoff frequency is implemented for flux estimation $[18,19]$ and a fuzzy logic speed control algorithm is proposed to improve the dynamic response of the drive [20]. Thus the aim of this paper is to enhance the steady state as well as the dynamic performance of the drive while maintaining the simplicity of control algorithm. The proposed control strategy is illustrated by simulation and validated through experimental results.

\footnotetext{
* University Institute of Technology, RGPV Bhopal, bhoopendrasingh1@gmail.com; ${ }^{* *}$ MANIT Bhopal, sjain68@gmail.com; *** Danfoss Power Electronics, Denmark, sanjeetkd@gmail.com
} 


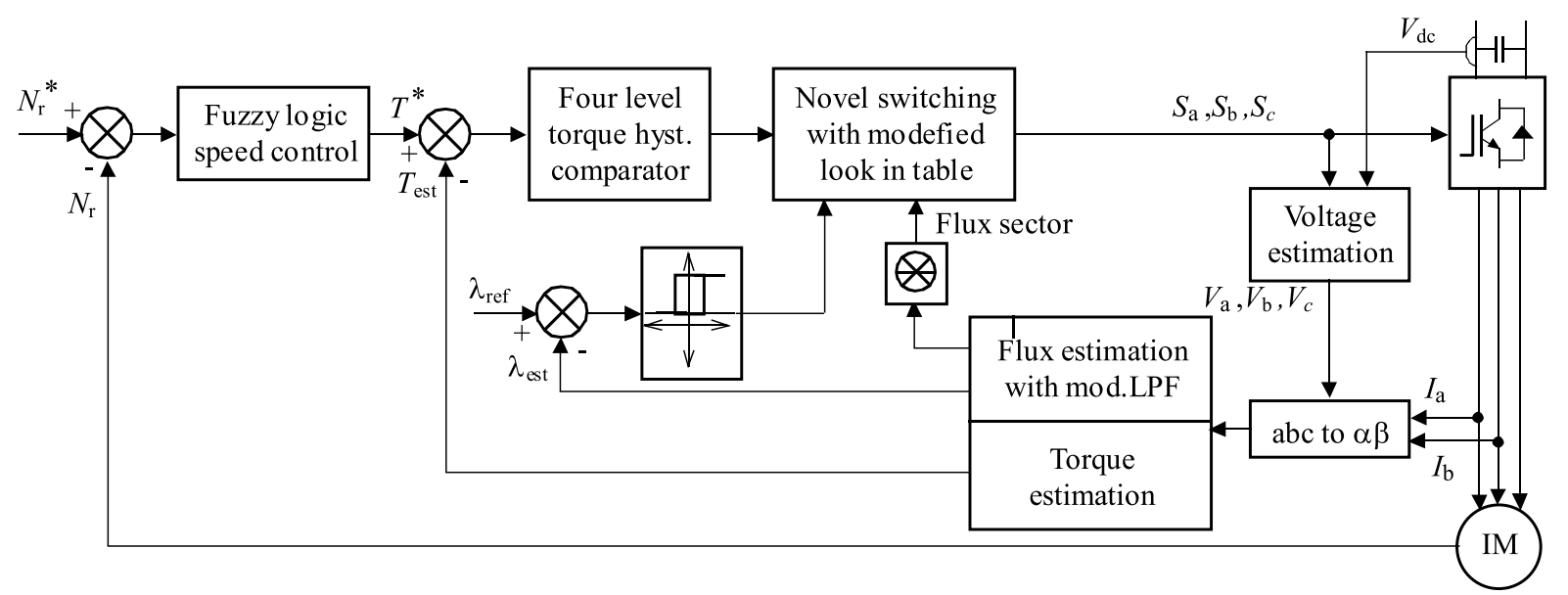

Fig. 1. Schematic diagram of the proposed DTC drive

(b)

(a)
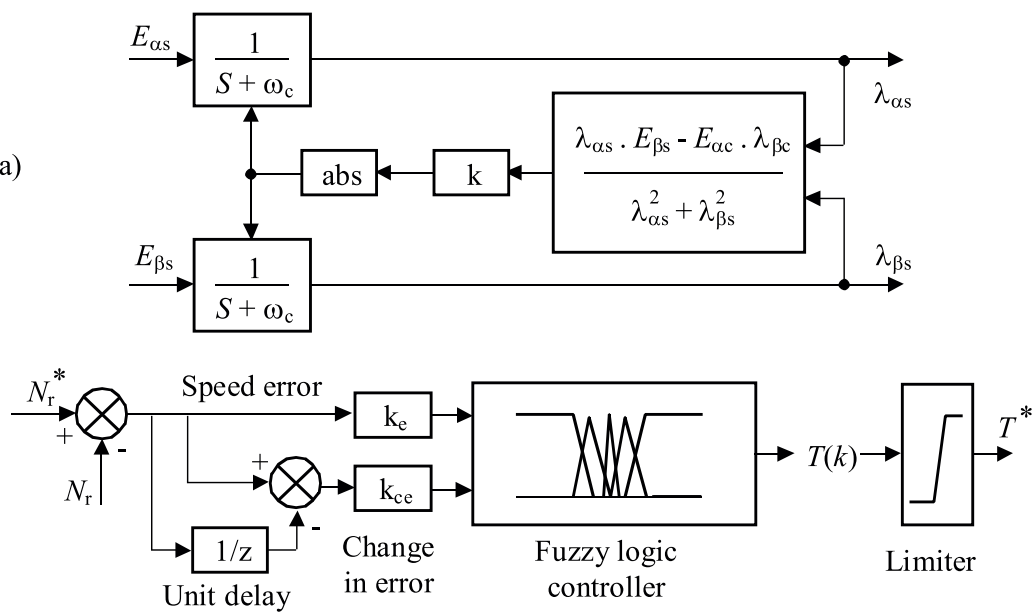

Fig. 2. (a) - Flux estimation by modified low pass filter, (b) - Fuzzy logic speed controller

\section{PROPOSED DTC SCHEME.}

The schematic block diagram of the proposed DTC drive is shown in Fig. 1. In the proposed scheme a fuzzy logic speed controller, which is explained in Section 2.2 in detail, is utilized in the speed control loop. For torque ripple reduction, the conventional switching scheme with limited voltage vectors is replaced by a modified scheme with larger number of voltage vectors. The details of the novel switching scheme are explained in Section 2.3.

From the basic equation governing induction motor operation stator flux $\lambda_{s}$ is given by

$$
\lambda_{s}=\int\left(V_{s}-R_{s} I_{s}\right) \mathrm{d} t
$$

For the estimation of stator flux, an integration operation is required as given by (1). A pure integrator has the following limitations.

1. Any transduction error in measured stator current due to offset introduces DC component and hence results in integrator saturation.

2. Integration error due to incorrect initial values.
To overcome the above mentioned limitations, a modified low pass filter based digital integration algorithm is implemented for flux estimation. The details of the flux estimation algorithm are explained in Section 2.1.

\subsection{Flux Estimation}

A well-known solution to the dc-offset and initial value problem with a pure integrator is to replace it with a low pass filter (LPF) with an appropriate cut off frequency. The mathematical expression of the low pass filter with a cut off frequency of $\omega_{c}$ can be given for $\xi=\alpha, \beta$

$$
\lambda_{s \xi}=\frac{1}{s+\omega_{c}}\left(E_{s \xi}\right)
$$

which can be expressed in discrete form as

$$
\lambda_{s \xi}(k)=\frac{1}{1+\Delta t_{s} \omega_{c}}\left(\Delta t_{s} E_{s \xi}(k)+\lambda_{s \xi}(k-1)\right),
$$

The value of the cutoff frequency $\omega_{c}$ has to be judicially chosen, because a cutoff frequency higher than operating frequency of the drive leads to flux distortion at low speeds. A possible solution to this problem is a modified LPF based flux estimator with cutoff frequency 

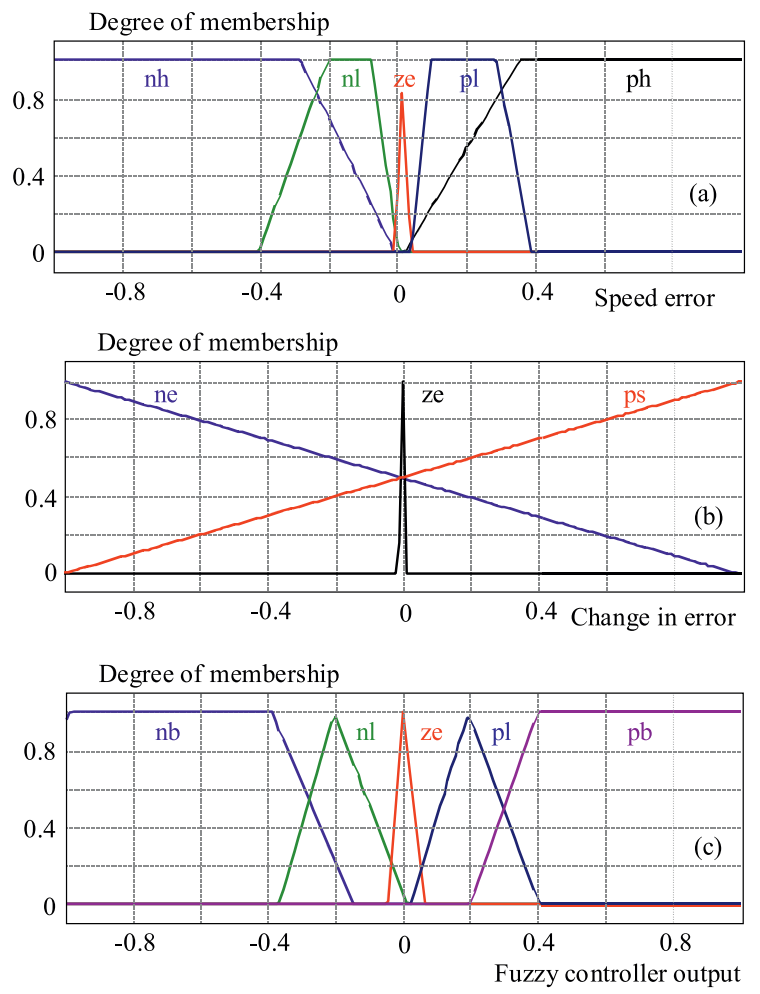

Fig. 3. Membership functions of FLC: (a) - input variable speed error, (b) - input variable change in speed error, (c- - output variable ref torque

Table 1. Fuzzy control rule table

\begin{tabular}{cccc}
\hline$\Delta E \backslash \Delta E$ & $\mathrm{NE}$ & $\mathrm{ZE}$ & $\mathrm{PS}$ \\
\hline $\mathrm{NH}$ & $\mathrm{NB}$ & $\mathrm{NB}$ & $\mathrm{NB}$ \\
$\mathrm{NL}$ & $\mathrm{NB}$ & $\mathrm{NL}$ & $\mathrm{NB}$ \\
$\mathrm{ZE}$ & $\mathrm{PL}$ & $\mathrm{PL}$ & $\mathrm{PL}$ \\
$\mathrm{PL}$ & $\mathrm{PB}$ & $\mathrm{PB}$ & $\mathrm{PB}$ \\
$\mathrm{PH}$ & $\mathrm{PB}$ & $\mathrm{PB}$ & $\mathrm{PB}$
\end{tabular}

Table 2. Proposed novel switching technique

\begin{tabular}{|c|c|c|c|c|c|}
\hline Flux & Torque & $\begin{array}{l}\text { Voltage } \\
\text { Vector }\end{array}$ & Flux & Torque & $\begin{array}{l}\text { Voltage } \\
\text { Vector }\end{array}$ \\
\hline & $\begin{array}{c}T \uparrow \uparrow \\
\text { (large increase) }\end{array}$ & $V_{2}$ & & $\begin{array}{c}T \uparrow \uparrow \\
\text { (large increase) }\end{array}$ & $V_{3}$ \\
\hline & $\begin{array}{c}T \uparrow \\
\text { (small increase) }\end{array}$ & $V_{12}$ & 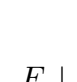 & $\begin{array}{c}T \uparrow \\
\text { (small increase) }\end{array}$ & $V_{34}$ \\
\hline 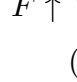 & $\begin{array}{c}T \downarrow \\
\text { (small decrease) }\end{array}$ & $V_{61}$ & . & $\begin{array}{c}T \downarrow \\
\text { (small decrease) }\end{array}$ & $V_{45}$ \\
\hline & $\begin{array}{c}T \downarrow \\
\text { (large decrease) }\end{array}$ & $V_{6}$ & & $\begin{array}{c}T \downarrow \downarrow \\
\text { (large decrease) }\end{array}$ & $V_{5}$ \\
\hline
\end{tabular}

proportional to the synchronous frequency, as shown in Fig.2(a) . The relation between the cutoff frequency and synchronous frequency $\omega_{e}$ can be given by a simple relation $\omega_{c}=k \omega_{e}$. The typical range of $k$ lies between 0.1 and 0.5 and the synchronous frequency can be given by (6).

$$
\omega_{e}=\frac{E_{s \beta} \lambda_{s \alpha}-E_{s \alpha} \lambda_{s \beta}}{\left|\lambda_{s}\right|^{2}}
$$

\subsection{Speed Control}

The schematic block diagram of the proposed fuzzy logic speed controller (FLC) is shown in Fig. 2(b). The basic consideration in the design of the control rules is aimed at a faster dynamic response of the drive while maintaining the simplicity of control. The two inputs to the FLC are speed error and change in speed error, which are expressed by (7) and (8) in discrete form for implementation on a dsp based controller.

$$
\begin{aligned}
& \Delta E(k)=N_{r}^{*}(k)-N_{r}(k), \\
& \Delta \dot{E}(k)=(\Delta E(k)-\Delta E(k-1)) / \Delta t .
\end{aligned}
$$

$\Delta E(k)$ is fuzzified into five fuzzy subsets, while $\dot{\Delta E}(k)$ is represented by three fuzzy subsets with triangular membership functions. The input and output membership functions are shown in Fig. 3. The universe of discourse for the two input fuzzy sets is taken as \pm 1 and the input variables are normalized by a normalized factor (Ke and Kce) so that they remain within the universe of discourse. The defuzzified output of the FLC is the reference torque command $T(k)$ which is further normalized so that the rated torque and current limits of the drive are not violated ( $\pm 6 \mathrm{Nm}, 2.0 \mathrm{amps})$.

The selection of membership function for the input and output variables as well as the formulation of the fuzzy rules is based on the prior knowledge of PI control in the speed control loop of a DTC drive through numerical simulation. The rules are formulated based on the fact that for a large positive speed error, the required control action is a higher value of torque command, while for a negative speed error a large negative torque command is desired. The set of rules for the proposed FLC are shown in Tab. 1.

\subsection{Novel switching technique}

A new method utilizing a larger number of synthesized intermediate voltage vectors with a modified look up table is proposed to overcome the limitations of the conventional DTC drive. In the proposed method, torque control is achieved by the application of full vectors $\left(V_{1}-\right.$ $\left.V_{6}\right)$ for large torque error and intermediate vectors $\left(V_{12}-\right.$ $V_{61}$ ) for smaller error between reference and estimated torque. The voltage vector selection algorithm shown in Tab. 2 can be verified from Fig. 4(a) when stator flux is located in sector 1 .

Large torque error can be minimized by a significant increment in the angular separation between stator and rotor flux vectors, which can be achieved by voltage vector $V_{2}$, however for a small increment in torque, the application of the intermediate voltage vector $V_{12}$ results in a smaller increment in the angular separation. It can be verified from the switching Table 2 that the proposed control algorithm is implemented by a four level torque comparator. A voltage vector $V_{12}$ can be synthesized by two adjacent full vectors $V_{1}$ and $V_{2}$ with $50 \%$ duty ratio.

An improvement in stator flux response at sector boundaries by the proposed technique can be explained 


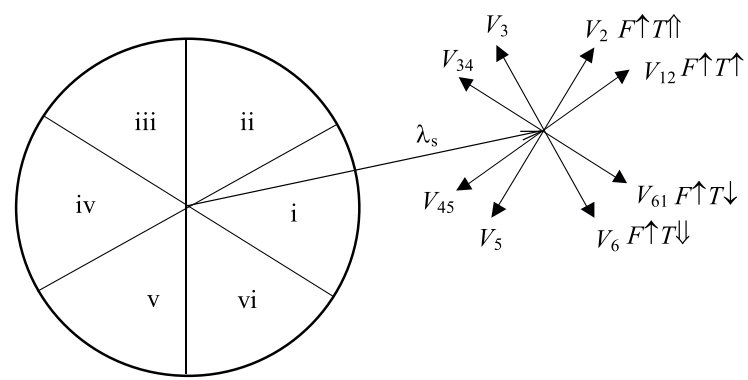

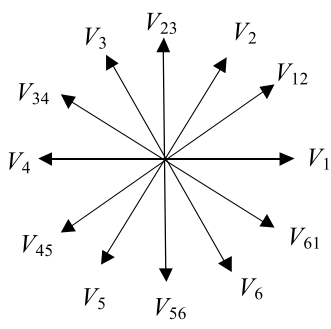

(b)

(a)

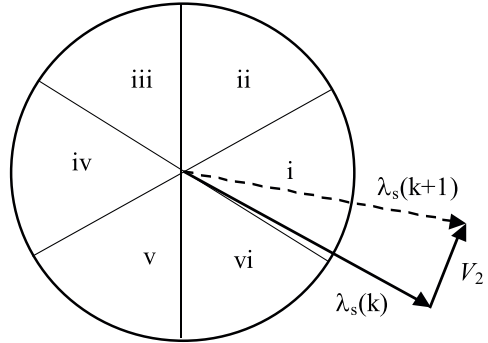

(c)

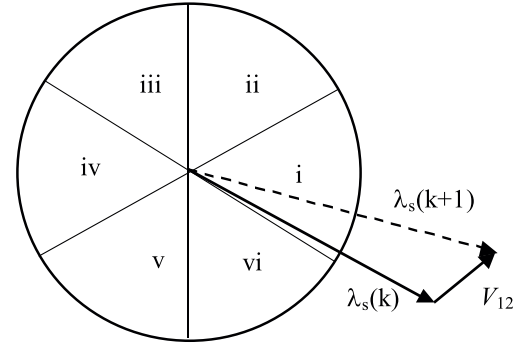

(d)

Fig. 4. (a) - Voltage vector selection in the proposed novel switching technique, (b) - Available voltage vectors, (c) - Flux droop at sector boundary by a full vector, (d) - Improved flux response by an intermediate vector

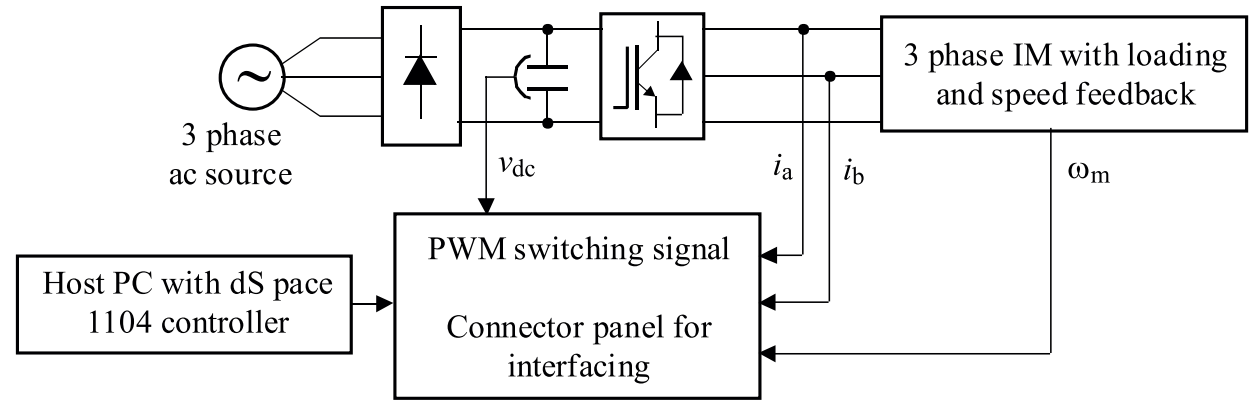

Fig. 5. Experimental test drive set up

from Fig. 4(b). The stator voltage vector $V_{2}$, which is selected for a torque and flux increment, becomes ineffective to boost the stator flux because the full voltage vector is almost orthogonal to the stator flux vector $\lambda_{s}(k)$. On the other hand it can be seen that the intermediate voltage vector $V_{12}$ can be more effective in increasing the resultant stator flux.

\section{RESULTS AND DISCUSSION}

The steady state as well as dynamic performance of the proposed drive are investigated through simulations using Matlab/Simulink and are further validated experimentally.

A test drive set up developed in the laboratory is shown in Fig. 5. The experimental test drive setup consists of the following elements:

1) Machine unit; a $0.75 \mathrm{~kW}, 410 \mathrm{~V}, 50 \mathrm{~Hz}$ squirrel-cage induction motor with a shaft mounted tachogenerator for speed sensing coupled with dc generator for loading.

2) A power module with MOSFET based voltage source inverter with Hall Effect sensors and gate drive circuitry. 3) dSpace DS1104 control board. The parameters of the motor for experimentation are as follows. $R_{s}=10.75 \Omega, R_{r}=9.28 \Omega, L_{s}=L_{r}=51.9 \mathrm{mH}, P=4$ and $L_{m}=479.9 \mathrm{mH}$. The sampling time of the DTC experiments is taken as $100 \mu$ s while the dead time for the switches is $10 \mu \mathrm{s}$. The value of torque and flux hysteresis comparator bandwidth is takes as $0.5 \mathrm{Nm}$ and $0.005 \mathrm{~Wb}$. All experimental results are recorded using the Control Desk platform of dSpace DS1104 by saving the target variable as mat files.

\subsection{Dynamic Perfomance}

The dynamic response of the drive was investigated by subjecting the drive to a speed reversal operation. Figure 6 shows the experimental and simulated results for a speed reversal at rated speed $(-1490 \mathrm{rpm}$ to $+1490 \mathrm{rpm})$. It can be verified from the experimental results that the time taken by the drive to attain steady state speed after reversal is approximately 2 secs. To further study the speed tracking performance, the drive was subjected to a continuous change in reference speed shown in Fig. 7 which is achieved by the control desk platform of dspace 

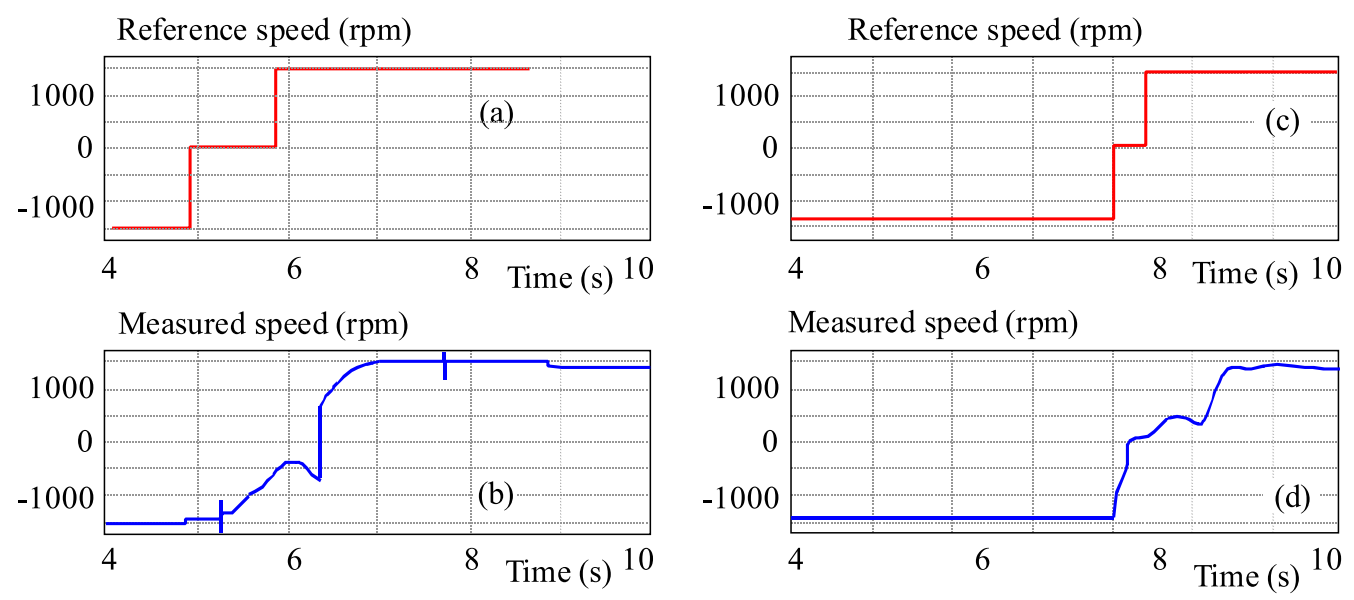

Fig. 6. Speed reversal dynamics for step change in speed command input from $-1490 \mathrm{rpm}$ to $1490 \mathrm{rpm}$ : (a) - ref.speed (experimental), (b) - measured rotor speed (experimental), (c) - ref.speed (simulation result), (d) - rotor speed (simulated)
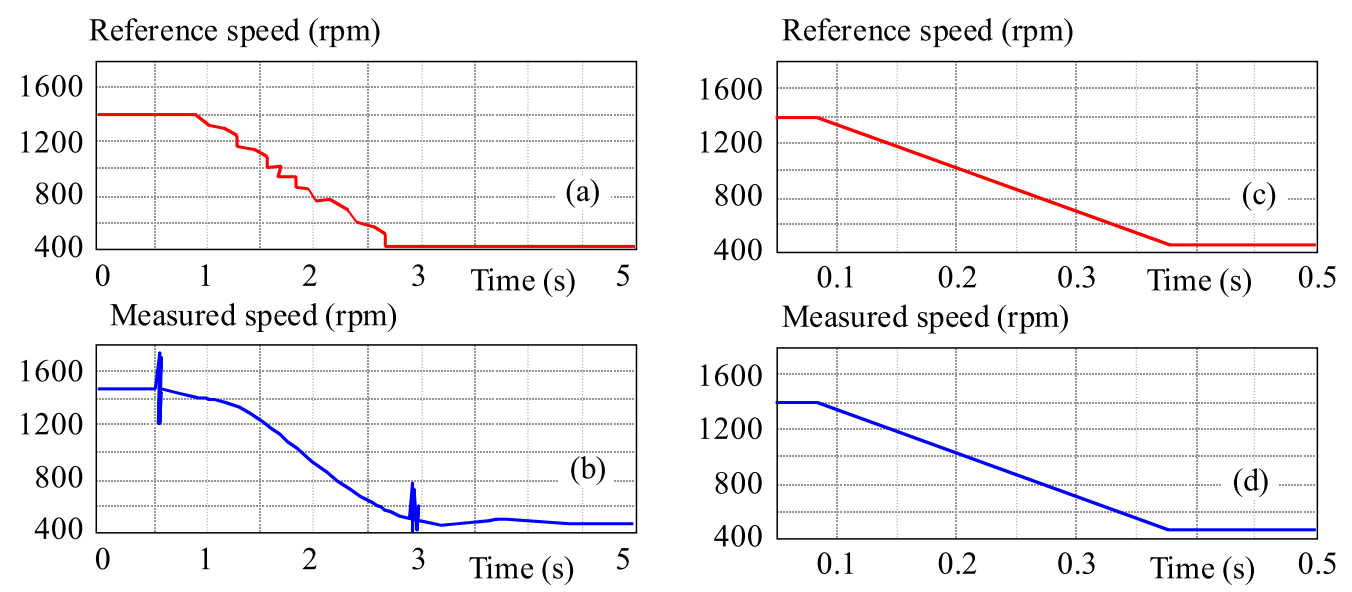

Fig. 7. Experimental and simulated speed tracking dynamics for continuous variation in speed command input (1400 rpm to $400 \mathrm{rpm}$ ): (a) - ref.speed (experimental), (b) - -measured rotor speed (experimental), (c) - ref.speed (simulation result), (d) - rotor speed (simulated)

having the feature of online change in an input parameter. From Fig.7(a) and 7(b) it can be seen that the actual rotor speed tracks the reference speed from $1400 \mathrm{rpm}$ to $400 \mathrm{rpm}$. Similar performance is also verified from the simulation results shown in Figs. $7(\mathrm{c})$ and $7(\mathrm{~d})$. Thus a fast dynamic response validates the superiority of the speed control algorithm.

\subsection{Steady State Perfomance}

\section{Torque Ripple Analysis}

The experimental test drive was operated in torque control mode under the influence of different reference torque (different operating speed) at $80 \%$ loading. The experimentation is primarily focused on low speed performance of the drive which is achieved by operating the drive with reference torque in the range from $1 \mathrm{Nm}$ to $1.8 \mathrm{Nm}$ The performance parameters to judge the effectiveness of the proposed method are torque and flux ripples which can be mathematically expressed by Root Mean Square Torque Error (RMSTE) and Root Mean Square Flux Error (RMSFE) given by (9) and (10). $\lambda_{s}(k)$ and $T_{e}(k)$ are the flux and estimated torque at $k^{\text {th }}$ sampling instant and $\lambda_{s}^{\text {ref }}$ is the reference stator flux and $T_{e}^{\text {avg }}$ is the calculated mean torque.

$$
\begin{aligned}
& R M S F E=\frac{1}{N} \sqrt{\sum_{k=1}^{N}\left(\lambda_{s}^{\mathrm{ref}}-\lambda_{s}(k)\right)^{2}}, \\
& R M S T E=\frac{1}{N} \sqrt{\sum_{k=1}^{N}\left(T_{e}^{\mathrm{avg}}-T_{e}(k)\right)^{2}} .
\end{aligned}
$$

A comparison of torque variation slope pattern can be done from Fig. 8(a) and (b). These simulation results shows the variation of estimated torque with the applied voltage vectors in conventional as well as the proposed technique. Comparing the two switching strategies, from Fig. 8(a) it can be seen that only a single full vector $V_{2}$ is responsible for torque increment in a particular sampling instant in conventional DTC, while in the proposed technique a full vector $V_{1}$ and an intermediate vector $V_{7}$ are selected for an increase in torque as shown by Fig. 8(b).

The superiority of the novel switching method over conventional method can be established from Fig. 9, which shows the experimental results for torque ripple 

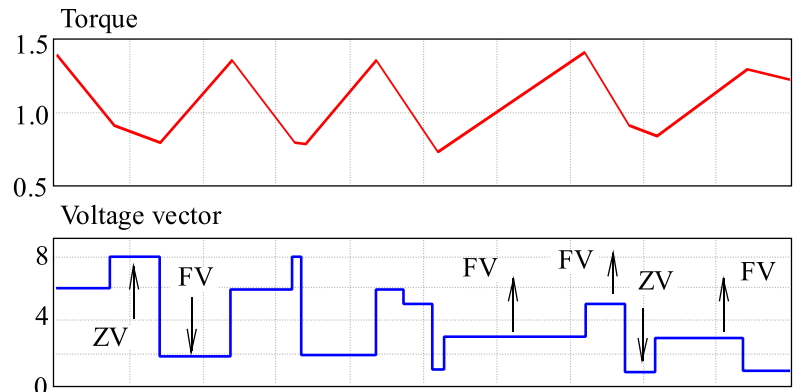

(a)

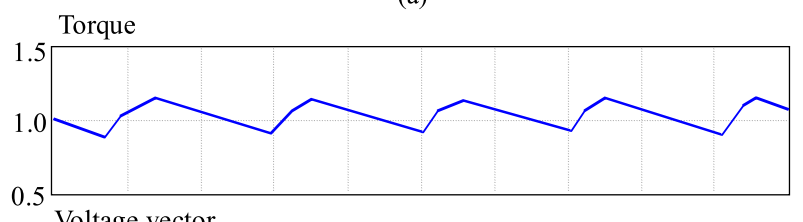

Voltage vector

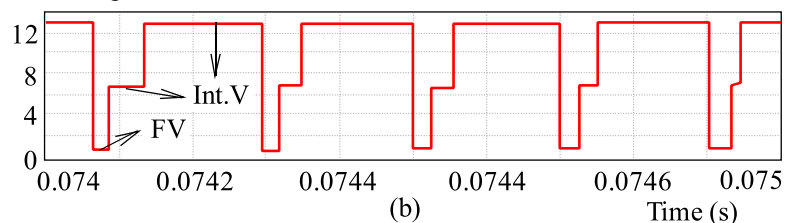

(b)

Time (s)

Fig. 8. Simulation results showing (a) - steep torque slope pattern with full vectors in conventional switching, (b) - improved torque slope pattern with intermediate vectors in novel switching method

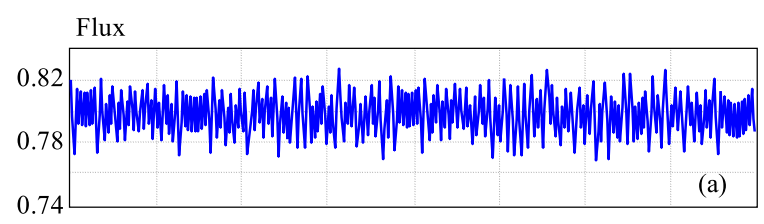

0.74

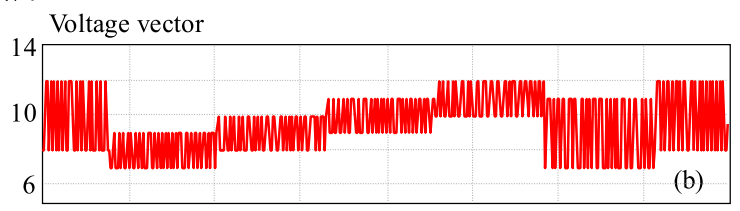

Flux sec.

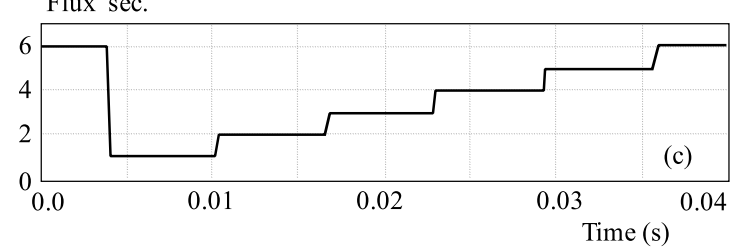

Fig. 10. Flux droop by zero vectors and sector transition in conventional DTC: (a) - flux, (b) - voltage vector, (c) - flux sector

comparison. The proposed novel switching technique exhibit a performance with reduced torque ripples at different operating torque ( $1 \mathrm{Nm}$ and $1.4 \mathrm{Nm}$ ).

The calculated torque and flux ripples at different operating torque on the collected data samples using control desk platform are presented in Table.3. It can be concluded from the table that by the proposed switching technique torque ripples get reduced by almost $60 \%$ as compared to conventional switching strategy. Furthermore a reduction in flux ripples can also be confirmed for the proposed strategy.

\section{Flux Response Analysis}

In a conventional DTC drive a droop in flux is observed when a change in stator flux sector takes place, and this
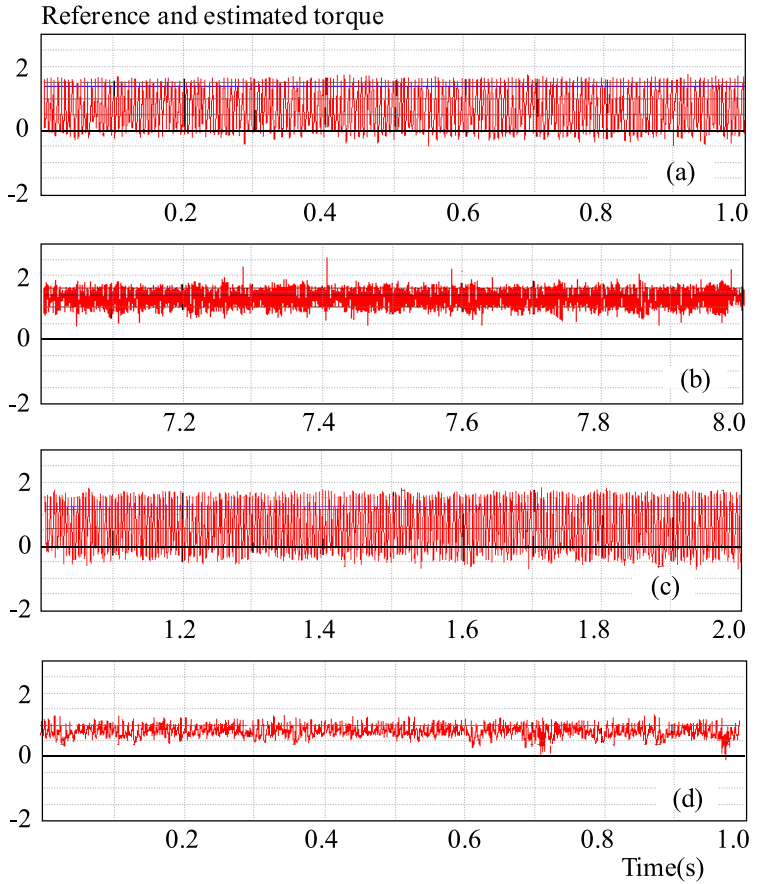

Fig. 9. Experimental torque ripple comparison for a ref torque of (a) $-1.4 \mathrm{Nm}$ conventional, (b) $-1.4 \mathrm{Nm}$ proposed novel technique, (c) $-1 \mathrm{Nm}$ Conventional switching technique, (d) $-1 \mathrm{Nm}$ proposed switching method

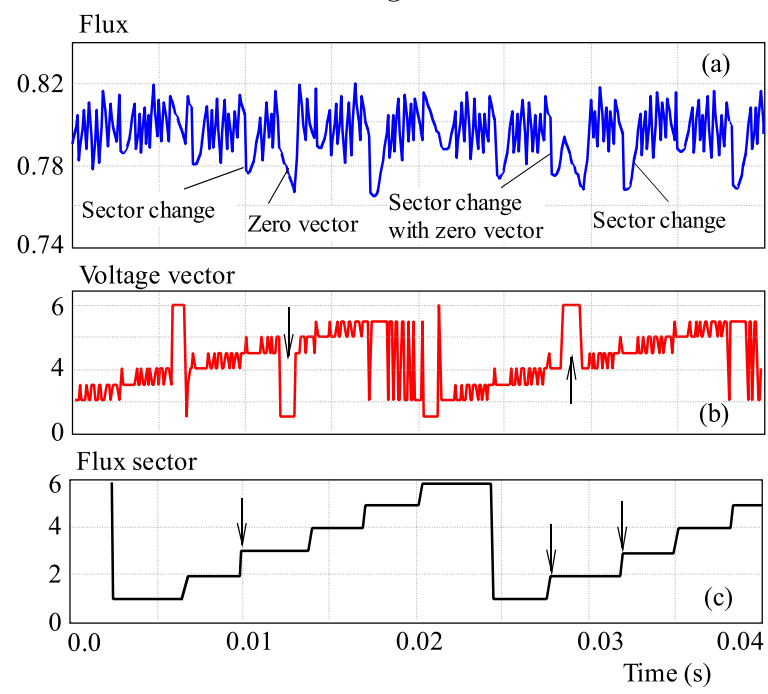

Fig. 11. Improved flux response at sector boundaries in novel switching technique: (a) - flux, (b) - voltage vector, (c) - flux sector

can be attributed to the fact that the effect of a chosen voltage vector for a particular flux requirement is different at sector boundaries. Furthermore zero voltage vectors, which are chosen for torque decrement also results in a significant droop in stator flux and it can be verified from Fig. 10 in which a plot of stator flux under the influence of different voltage vectors along with stator flux location is shown.

The arrow marks in the figure points the instants of sector change and application of zero voltage vectors and the corresponding distortion in stator flux. On the contrary as shown in Fig. 11 an improved flux response in terms of elimination of flux droop at sector boundaries and a minimization in flux distortion due to zero voltage vectors validate the superiority of the modified method 

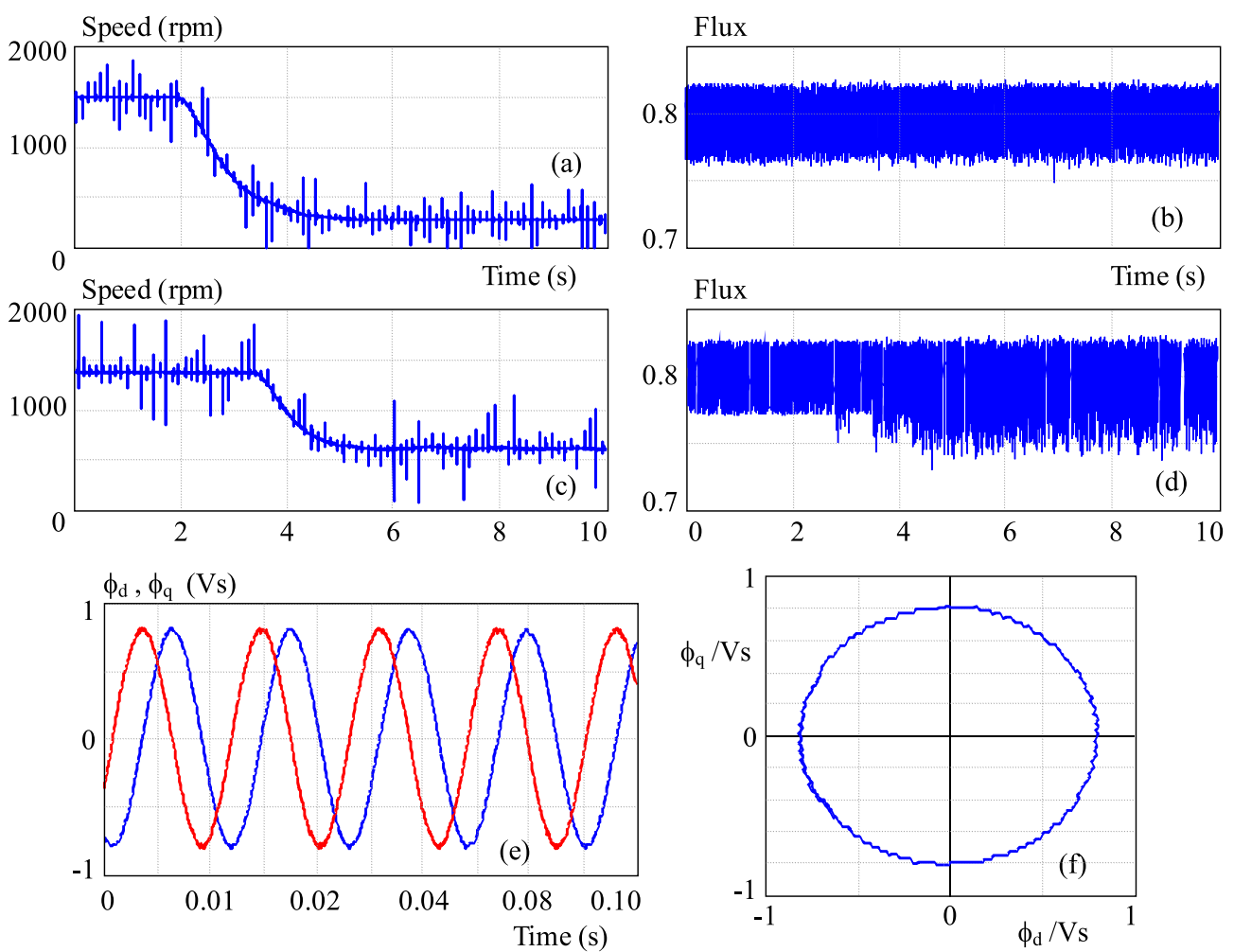

Fig. 12. Experimental results to validate the effectiveness of the flux estimation algorithm (a) - speed in rpm, (b) - flux response for step reduction in operating speed for modefied LPF method, (c) - speed in rpm, (d) - flux response of conventional LPF method, (e) - steady state Stator flux components $\left(\lambda_{s \alpha}, \lambda_{s \beta}\right)(f)$ flux trajectory

Table 3. Torque and flux ripple comparison

\begin{tabular}{|c|c|c|c|c|}
\hline \multirow{3}{*}{$\begin{array}{l}\text { Switching } \\
\text { techniques }\end{array}$} & \multicolumn{3}{|c|}{ Performance Comparison } & \multirow{3}{*}{$\begin{array}{l}\text { Flux } \\
\text { Ripple }\end{array}$} \\
\hline & \multirow[b]{2}{*}{$\begin{array}{c}\text { Reference } \\
\text { Torque } \\
\text { Nm }\end{array}$} & \multicolumn{2}{|c|}{ Torque Ripple } & \\
\hline & & $\mathrm{Nm}$ & $\begin{array}{l}\mathrm{Pu} \text { of } \\
\text { mean } \\
\text { torque }\end{array}$ & \\
\hline \multirow{4}{*}{ Conventional } & 1.0 & 0.7431 & 2.32 & 0.0199 \\
\hline & 1.3 & 0.59 & 0.91 & 0.0144 \\
\hline & 1.5 & 0.6156 & 0.8347 & 0.0136 \\
\hline & 1.7 & .7855 & 1.13 & .0145 \\
\hline \multirow{4}{*}{ Proposed } & 1.0 & 0.1962 & 0.2290 & 0.0135 \\
\hline & 1.3 & 0.2084 & 0.1740 & 0.0136 \\
\hline & 1.5 & 0.2499 & 0.27 & 0.0130 \\
\hline & 1.8 & .2383 & .2072 & .0134 \\
\hline
\end{tabular}

over conventional DTC. The performance parameters to evaluate the effectiveness of the integration algorithm for flux estimation are steady state and dynamic flux response. A comparison of conventional LPF based integrator and proposed modified low pass filter method, when the drive is subjected to a step reduction in speed is shown in Fig. 12 .

It can be verified from Fig. 12(d) that the flux ripples in a conventional LPF increases when there is a sudden reduction in speed, which is one of the limitations of a LPF having a fix cutoff frequency. In a modified low pass filter, the cut off frequency depends upon the operating synchronous frequency and hence the flux ripples remains within the hysteresis band when the drive is subjected to a step reduction in operating speed from $100 \%$ to $17 \%$ of its rated speed, as see in Fig. 12(b). The calculated RMSFE during speed decrement for the modified low pass filter is $1.55 \%$ while it is $2.25 \%$ for LPF.

Figures $12(\mathrm{e})$ and (f) shows steady state flux response. From Fig. 12(e) it can be verified that the two stator flux components are orthogonal and are sinusoidally varying with time. A circular flux trajectory shown in Fig. 12(f) further validates the effectiveness of the flux estimation method.

The investigations on the proposed DTC drive are summarized in Table 4.

\section{Table 4.}

\begin{tabular}{c|l}
\hline $\begin{array}{c}\text { Performance } \\
\text { parameters }\end{array}$ & Remarks \\
\hline Torque Ripple & Torque ripple reduction by $60 \%$ \\
\hline Flux Response & $\begin{array}{l}\text { Improved flux response in terms of } \\
\text { 1. Absence of flux drop at sector boundaries } \\
\text { with reduced flux ripples due to selected } \\
\text { intermediate voltage vectors and modi- } \\
\text { fied flux estimation method having tunable } \\
\\
\text { cutoff frequency } \\
\text { 2. Circular stator flux trajectory }\end{array}$ \\
\hline Speed control & $\begin{array}{l}\text { A fast dynamic response with fuzzy logic } \\
\text { speed controller }\end{array}$ \\
\hline
\end{tabular}




\section{CONCLUSION}

An enhancement in steady state performance of a DTC drive is achieved by a novel switching technique with a modified look up table incorporated with a larger number of voltage vectors. The proposed technique proves superior to conventional method with reduced torque ripples by almost $60 \%$. An improved flux response at sector transition during low speed operation has also been achieved by the proposed technique. Implementation of fuzzy logic control in speed control loop has resulted into a fast dynamic response of the drive.

\section{REFERENCES}

[1] TAKAHASHI, I.-NOGUCHI, T.: A New Quick-Response and High Efficiency Control Strategy of Induction Motor, IEEE Transactions on Industrial application 22 No. 5 (1986), 820-827.

[2] DEPEnBROK, M.: Direct Self-Control (DSC) of Inverter-Fed Induction Machine, IEEE Trans. Power Electron. 3 No. 4 (Oct 1988), 420-429.

[3] BUJA, G. S.-KAZMIERKOWSKI, M. P. : Direct Torque Control of a PWM Inverter-Fed AC Motors - A Survey, IEEE Trans. Ind. Electron. IE-51 No. 4 (Aug 2004), 744-757.

[4] KANG, J.-SUL, S.: Analysis and Prediction of Inverter Switching Frequency in Direct Torque Control of Induction Machine based on Hysteresis Bands and Machine Parameters, IEEE Trans. Ind. Electron. 48 No. 3 (Jun 2001), 545-553.

[5] Habetlen, T. G.-Profumo, F.-PASTORELli, M.TOLBERT, M.: Direct Torque Control of Induction Machines using Space Vector Modulation, IEEE Trans. Ind. Applicat. 28 No. 5 (Sep/Oct 1992), 1045-1053.

[6] LAI, Y. S.-CHEN, J. H. : A New Approach to Direct Torque Control of Induction Motor Drives for Constant Inverter Switching Frequency and Torque Ripple Reduction, IEEE Trans. Energy Convers. 16 (2001), 220.

[7] CASADEI, D.-SERRA, G.-TANI, A. : Implementation of a Direct Torque Control Algorithm for Induction Motors based on Discrete Space Vector Modulation, IEEE Trans. Power Electron. 15 No. 4 (July 2000), 769-777.

[8] ZHANG, Y.-ZHU, J.-ZHAO, Z.-XU, W.-DRROELL, D. G. : An Improved Direct Torque Control for Three-Level Inverter-Fed Induction Motor Sensorless Drive, IEEE Trans Power Electron 26 No. 7 (July 2011).

[9] LEE, K.-B.-SONG, J.-H.-CHOY, I.-YOO, J.-Y.: Torque Ripple Reduction in DTC of Induction Motor Driven by ThreeLevel Inverter with Low Switching Frequency, IEEE Trans. Power Electron 17 No. 2 (Mar 2002), 255-264.

[10] KOURO, S.-BERNAL, R.-MIRANDA, H.-SILVA, C. A.RODRIGUEZ, J.: High Performance Torque and Flux Control for Multilevel Inverter Fed Induction Motors, IEEE Trans. Power Electron. 22 No. 6 (Nov 2007), 2116-2123.

[11] del TORO, X.-ARIAS, G. A.-JAYNE, M.-WITTING, P.: Direct Torque Control of Induction Motors Utilizing Three-Level Voltage Source Inverters, IEEE Trans.Ind. Electron. 55 No. 2 (Feb 2008), 956-958.

[12] LAI, Y. S.-WANG, W. K.-CHEN, J. H.: Novel Switching Techniques for Reducing the Speed Ripple of AC Drives with
Direct Torque Control, IEEE Trans. Ind. Electron. 51 No. 4 (Aug 2004), 768-775.

13] ROMERAL, L.-ARIAS, A.-ALDABAS, E.-JAYNE, M.: Novel Direct Torque Control (DTC) Scheme with Fuzzy Adaptive Torque-Ripple Reduction, IEEE Trans. Ind. Electron. 50 No. 3 (2003), 487-492.

14] ZHANG, Y.-ZHU, J.: A Novel Duty Cycle Control Strategy to Reduce Both Torque and Flux Ripples for DTC of Permanent Magnet Synchronous Motor Drives With Switching Frequency Reduction, IEEE Trans. Power Electron. 26 No. 10 (Oct 2011), 3055-3067.

[15] AMBROZIC, V.-BUJA, G. S.-MENISR. : Band-Constrained Technique for Direct Torque Control of Induction Motor, IEEE Trans. Ind. Electron. 51 No. 4 (2004), 776-784.

[16] WONG, W. S. H.-HOLLIDAY, D.: Minimisation of Flux Droop in Direct Torque Controlled Induction Motor Drives, IEEE Proc Electr Power Appl. 151 No. 6 (Nov 2004), 694-703.

[17] LEE, K. B.-SONG, J. H.-CHOY, I.-YOO, J. Y.: Torque Ripple Reduction in DTC of Induction Motor Driven by ThreeLevel Inverter with Low Switching Frequency, IEEE Trans. Power Electron. 17 No. 2 (Mar 2002), 255-264.

18] HU, J.-WU, B.: New Integration Algorithms for Estimating Motor Flux over a Wide Speed Range, IEEE Trans. Power Electron. 13 (Sep 1998), 969-977.

[19] HINKKANEN, M.-LUOMI, J. : Modified Integrator for Voltage Model Flux Estimation of Induction Motors, IEEE Trans. Ind. Electronics 50, No. 4 (Aug 2003).

[20] YANG, J.-Q.-HUANG, J.: Direct Torque Control System for Induction Motors with Fuzzy Speed PI Regulator, Proceedings of the Fourth International Conference on Machine Learning and Cybernetics, Guangzhou, 18-21 August 2005, pp. 778-783.

Received 27 June 2012

Bhoopendra Singh was born in1972 in India. He graduated in electrical engineering and gained his MTech and $\mathrm{PhD}$ in electrical engineering from National Institute of Technology Bhopal (MANIT) in 2005 and 2013 respectively. He is an asst. professor at the Faculty of Electrical Engineering, University Institute of Technology, RGTU Bhopal. His professional and research interests include power electronics and control of electrical drives.

Shailendra Jain received his BE, ME and PhD degree in 1990, 1994 and 2003 respectively, and PDF from UWO London, ON, Canada in 2007. He is working as Professor at the Department of Electrical Engineering, NIT, Bhopal, India. Dr Jain is the recipient of Career Award for Young Teachers given by AICTE New Delhi, India for the year 2003-2004. His research interests include power electronics and electric drives, power quality improvement, active power filters, high-power factor converters, Multilevel Inverters and fuel cell based distributed generation.

Sanjeet Dwivedi received his ME degree (with Gold Medal) from the University of Roorkee, Roorkee, India in 1999 and PhD degree in 2006 from IIT Delhi. He is currently associated with Control Engineering Global R\&D European Design Center Danfoss Power Electronics, Denmark. His research interests are in area of, digital control of Permanent Magnet Brushless Motors, sensor reduction techniques in ac drives and power quality improvement aspects of ac drives. 